\title{
Reconfigurable Dielectric Resonator Antenna Using an Inverted U-shaped Slot
}

\author{
Mohammad Abediankasgari, Mohsen Khalily, Shadi Danesh, Pei Xiao, and Rahim Tafazolli \\ Institute for Communication Systems (ICS), Home of the 5G Innovation Centre (5GIC), University of Surrey, Guildford, UK \\ m.adebiankasgari@surrey.ac.uk
}

\begin{abstract}
A novel reconfigurable dielectric resonator antenna (DRA) employed a T-Shaped microstrip-fed structure in order to excite the dielectric resonator is presented. By carefully adjusting the location of the inverted U-shaped slot, switches, and length of arms, the proposed antenna can support WLAN wireless system. In addition, the presented DRA can be proper for cognitive radio because of availability switching between wideband and narrowband operation. The proposed reconfigurable DRA consisting of a Roger substrate with relative permittivity 3 and a size of $20 \mathrm{~mm} \times 30 \mathrm{~mm} \times 0.75 \mathrm{~mm}$ and a dielectric resonator (DR) with a thickness of $9 \mathrm{~mm}$ and the overall size of $18 \mathrm{~mm} \times 18 \mathrm{~mm}$. Moreover, the antenna has been fabricated and tested, which test results have enjoyed a good agreement with the simulated results. As well as this, the measured and simulated results show the reconfigurability that the proposed DRA provides a dual-mode operation and also three different resonance frequencies as a result of switching the place of arms.
\end{abstract}

Keywords-cognitive radio, dielectrics resonator antenna, reconfigurable, WLAN

\section{INTRODUCTION}

Dielectric resonator antennas proposed in 1983 have been gaining a great deal of interest owing to their useful features like compact size, easy excitation methods, large impedance bandwidth, high radiation efficiency [1-4]. They have high efficiency due to low losses and absent conduction losses. Moreover, the DRAs can be designed by various shapes and excited by different feeding mechanisms such as microstrip feed-lines and coaxial probe [5-8]. Additionally, the DRAs have been used for wideband, dual-band, and multi-band applications [9-11]. In [6], a novel form of dielectric resonator antenna having a P-shaped figure is introduced for wideband wireless applications with $80 \%$ bandwidth. The axial ratio (AR), reflection coefficient, radiation patterns, gain, and efficiency of a rectangular dielectric resonator that enjoy a wideband circularly polarized excited by feed-lines, is studied in [7]. As well as this, in [8], a square DRA, which is excited by the coaxial probe, with two unequal inclined slits that excite a circularly polarized mode, is presented, and it offers an impedance bandwidth around $3.7 \mathrm{GHz}$, gain between 4 and $6 \mathrm{dBi}$. By employing a suitable tapered strip excitation in [9], an enhancement in bandwidth, $96 \%$, is obtained. A modified planar DRA excited by a microstrip feed extended like a probe in the vicinity of the DR for dual and wideband frequency applications [10]. This author, furthermore, introduces a multi-band printed dielectric resonator monopole antenna (PDRMA) fed by a printed fork-like stepped monopole antenna, which excites two new modified cylindrical dielectric resonators that leads to achieving multiband operation with VSWR less than two [11]. Moreover, one of the major challenges in this type of antennas is increasing the impedance bandwidth, while obtaining stable radiation patterns. Generally, 10-15\% bandwidth can be provided by a single-mode operation DRA, which clearly not enough for most of the wideband applications because of wideband operation based on multiple modes that lead to a variation of the patterns over the bandwidth. This problem, bandwidth limitation, can be tackled by adopting a number of techniques in order to alleviate the DRA operation bandwidth [12-21]. Various techniques are introduced in [12-21] such as applying into practice a ring dielectric resonator excited by annularshaped microstrip in [20], employing a modified structure of the DR like E-shaped [15], U-shaped [14], triangular [16], Tshaped and cross-T-shaped [17], [12] or implementing embedded dielectric resonator $[18,19]$ and applying aperture couple cylindrical DRs [21]. On the other hand, frequency agility is now an emerging need for modern wireless communication systems. Re-configurability is achieved by altering the antenna characteristics by changing the flow of current on an antenna, using phase shifters, mechanically movable parts attenuators, tunable materials, diodes, or active materials. In [5], for instance, by using radio frequency PIN diodes and placing on the feed line network, switchers are used to stimulating antenna, which creates a frequency tunable DRA. Reconfigurable antenna modifies the antenna's frequency bandwidth, radiation patterns, polarization, in some anticipated ways. For example, a reconfigurable antenna can be designed to shift the beam in the desired direction, place a null in a certain direction to reduce interference, change the resonance frequency or change the polarization from linear to circular. Recently, reconfigurable dielectric resonator antennas have been presented in the literature for frequency control [21], [22], and [24]. A rectangular DRA that is able to switch between two different frequencies, $4.12 \mathrm{GHz}$ and 8.85 $\mathrm{GHz}$, is introduced in [24]. This reconfigurable dielectric resonator antenna works in different bands by setting the switch on the connecting lines of a network that feeds the dielectric element and changing the state of switch from ON to OFF, a shift of the well-matched operating frequency range is obtained. In [25] an air-filled channel between dielectric resonator antenna and the plane of the ground is introduced, which can lead a frequency shift to lower frequencies by employing a slide metalized dielectric slugs under the DR. Another technique that brings about a reconfigurable DRA is the use of the switches on the way of feed line to create some dual-band and narrowband frequency [26], [27]. However, by using different types of electronic devices such as field-effect 


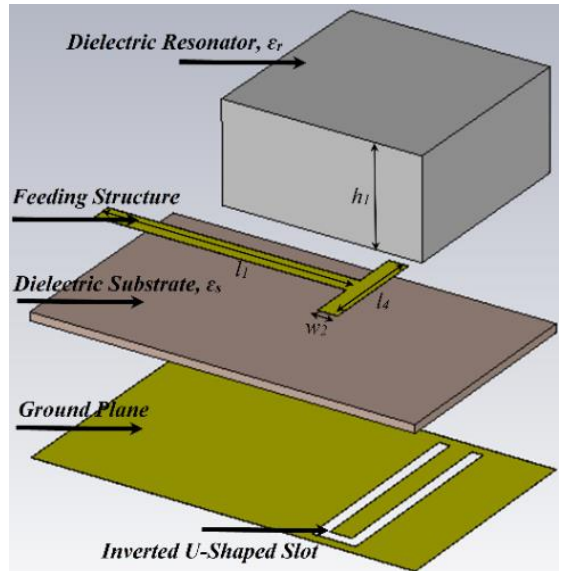

(a)

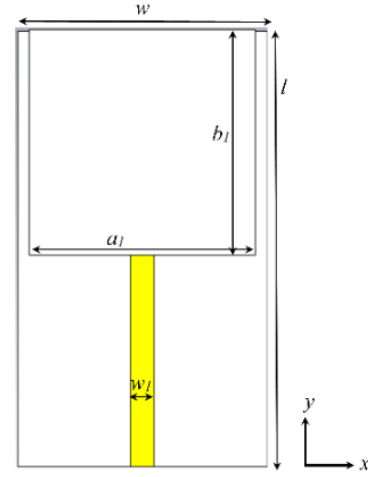

(b)

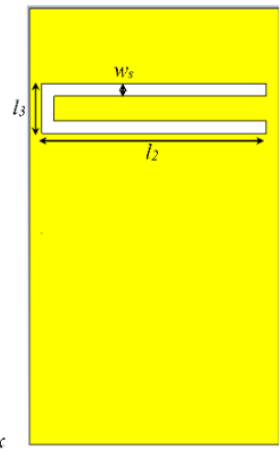

(c)
Fig. 1. Structure of the proposed reconfigurable DRA (a) exploded view, (b) front view, and (c) back view. $\left(l=l_{g}=30, w=w_{g}=20, w_{s}=1, l_{1}=23, l_{2}=\right.$ $18, l_{3}=4, l_{4}=10, w_{1}=1.9, w_{2}=1.8, a_{1}=18, b_{1}=18, h_{1}=9, \varepsilon_{r}=12.2, \varepsilon_{s}$ $=3, s=0.75$. Unit: mm.)

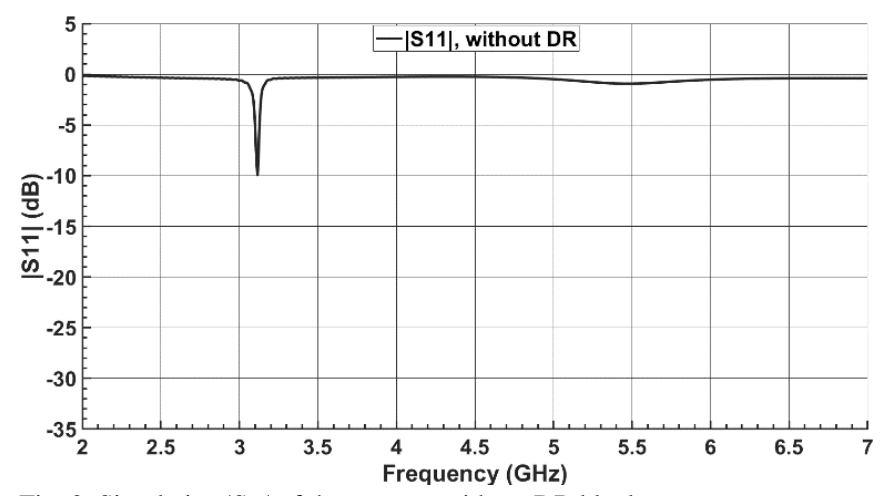

Fig. 2. Simulation $\left|S_{11}\right|$ of the antenna without DR block.

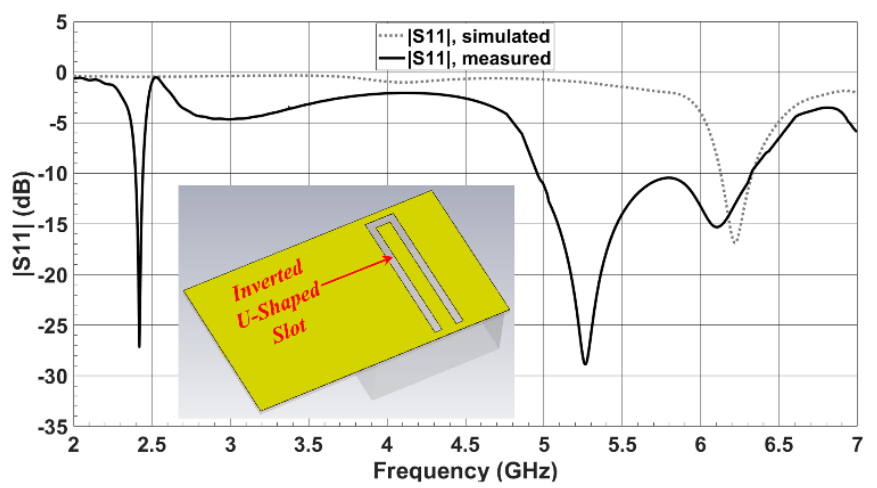

Fig. 3. Simulated $\left|S_{11}\right|$ of the proposed DRA with and without slot. transistors (FETs), microelectromechanical system switches (MEMS), or PIN diodes can attain discrete tunable frequency [28], [29]. In this paper, a new frequency reconfigurable DRA for the WLAN application is presented. By employing an inverted U-shaped slot, controlling the resonance frequencies and bandwidth reconfiguration are obtained. In order to validate the functionality, a fully well-designed prototype was fabricated and measured.

\section{ANTENNA CONFIGURATION}

The proposed antenna is shown in Fig.1. The antenna system consists of a Roger 3003 substrate with relative permittivity, $\varepsilon_{r}$, of 3 , and a size of $20 \mathrm{~mm}$ (x-axis) $\times 30 \mathrm{~mm}$ (yaxis) $\times 0.75 \mathrm{~mm}$. A ground plane is etched on the bottom side of the substrate, having the same area as the substrate. An inverted U-shaped slot has been created in the upper part of the ground plane for efficient coupling of EM energy to the DR and also for frequency reconfigurability. The DR is fed by using a T-shaped microstrip feeding structure. The relative permittivity of the DR is 12.2 , with a total size of $18 \mathrm{~mm} \times 18$ $m m \times 9 m m$ (z-axis).

\section{EFFECT OF DIELECTRIC RESONATOR}

In this section, first of all, the $\left|S_{11}\right|$ of the proposed antenna without the DR block is studied with the aid of practical software CST microwave studio suite 2019, shown in Fig. 2.

As illustrated in Fig. 2, when the dielectric resonator is not employed, a total mismatch of the antenna in the whole frequency band is clear. In other words, in this initial state of designing antenna without the DR, the impedance characteristic and the related matching are inferior. Therefore, the proposed feeding configuration is only used to excite the DR.

The effect of the DR with (denote as the case I) and without slot on the frequency bandwidth of the antenna is investigated separately, which results are shown in Fig. 3. As can be clearly seen from Fig. 3, by employing the DR on the feed line and applying an inverted U-shaped slot (case I)), a dual-band operation (2.39-2.46 GHz (narrowband) and 4.96$6.32 \mathrm{GHz}$ (wideband)) is obtained due to exciting three vertically polarized modes $T E^{x}{ }_{111}, T E^{x}{ }_{121}$ and $T E^{x}{ }_{131}$ inside the DRA at $2.4 \mathrm{GH}, 5.2 \mathrm{GHz}$, and $6.1 \mathrm{GHz}$ respectively.

\section{DESIGN OF RECONFIGURABILITY}

Figure 4 illustrates the geometry of two cases of reconfigurability of the proposed antenna. In fact, to have a reconfigurable DRA, two switches are deployed in the Ushaped slot. Case II, as shown in Fig. 4 (a), when the first switch is placed in the lower-left edge of the slot shown in Fig. 4 (a). In this case, the separation between the corresponding resonant frequencies of the excited $T E^{x}{ }_{121}$ (at $5.5 \mathrm{GHz}$ ) and $T E^{x}{ }_{131}$ (at $6.35 \mathrm{GHz}$ ) modes is decreased while the first dominant $T E^{x}{ }_{111}$ is degraded. Case III is shown in Fig. 4(b), referring to the case that by applying the second switch, a narrowband operation at $5.8 \mathrm{GHz}$ corresponding to the $T E^{x}{ }_{131}$ mode is obtained. The simulated results of case II and III are shown in Fig. 5 and 6, respectively. It can be seen from Fig. 5 and 6 that by separately implementing the first and second switches, the triple-band operation (case I) change to wideband and single-band in case II and case III, respectively. 


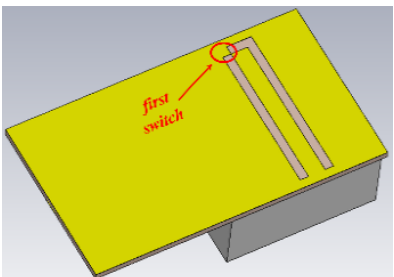

(a)

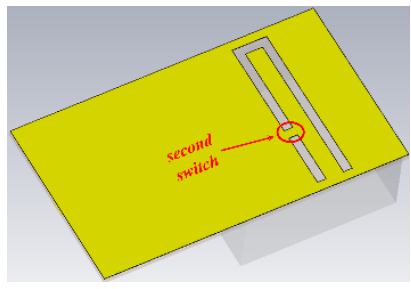

(b)
Fig. 4. Different positions of the switches in the ground plane (a) case II, (b) case III.

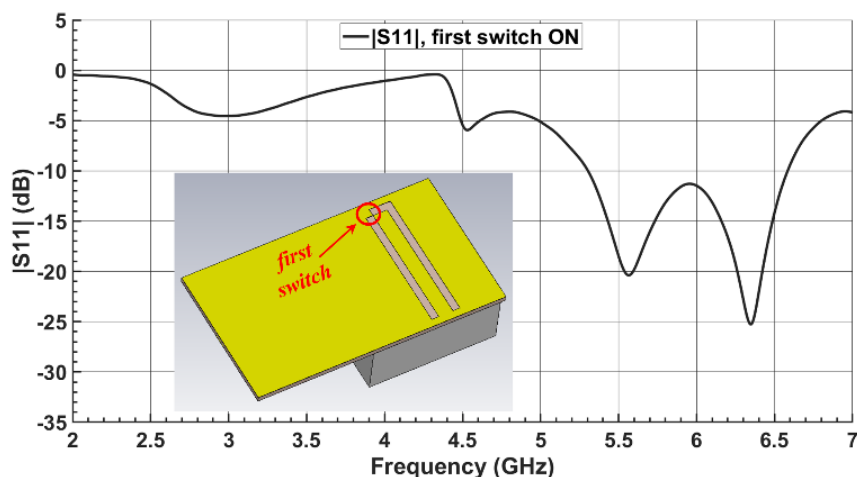

Fig. 5. Simulated $\left|S_{11}\right|$ of the DRA when the first switch is ON (case II).

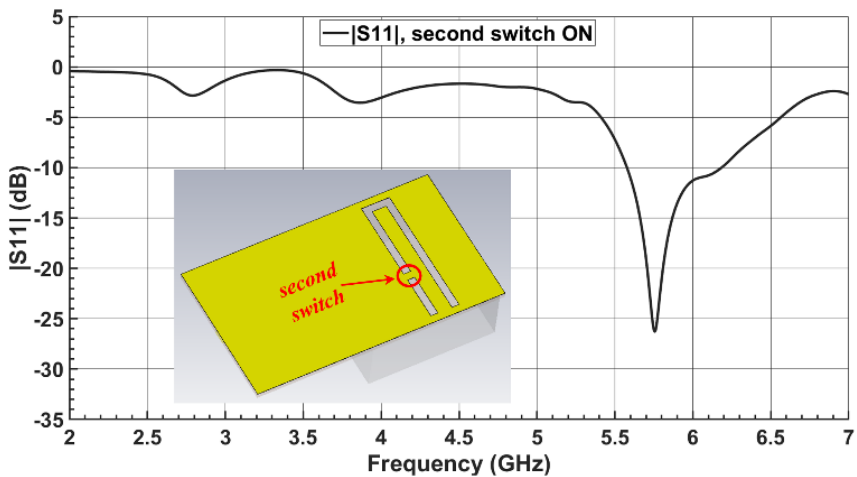

Fig. 6. Simulated $\left|S_{11}\right|$ of the DRA when the second switch is ON (case III).

\section{RESULTS AND DISCUSSIONS}

A fully functional prototype of 3 different forms of antennas, U-shaped slot without switching (case I), case II, and case III, has been fabricated and measured to verify the proposed design, shown in Fig. 7. Due to verifying the performance of the DRA in terms of the $\left|S_{11}\right|$, all states of proposed dielectric resonator antennas are measured and compared with simulated ones, shown in Figs. 8, 9, and 10. Results have been obtained based on the proposed design procedure. Generally, the return loss amount matches well in simulation and experimental results, but some differences between simulation and experimental results are visible, which is mainly due to the test environment that causes frequency shift.

Table I shows the simulated radiation efficiency and measured the gain of the proposed antenna with and without the DR. As can be clearly seen from the table, the antenna radiation efficiency remains more than $90 \%$, and the gain of the antenna is more than $2.89 \mathrm{~dB}$ at the desired frequencies.

Fig. 9 and Fig. 10 show the measured results of two different states of the proposed antenna that each one provides different $\left|S_{11}\right|$, which can be employed in various applications.

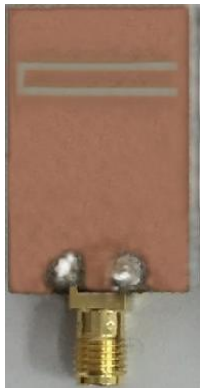

(a)

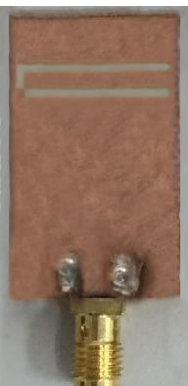

(b)

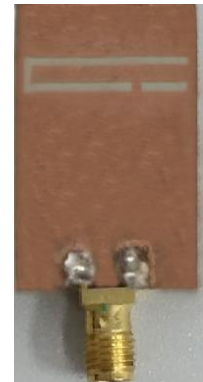

(c)

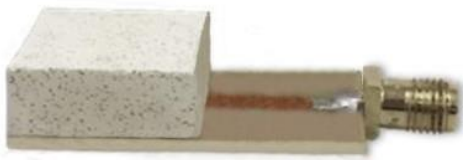

(d)

Fig. 7. Photograph of the fabricated reconfigurable DR antenna (a) case I, (b) case II, (c) case III, and (d) side view.

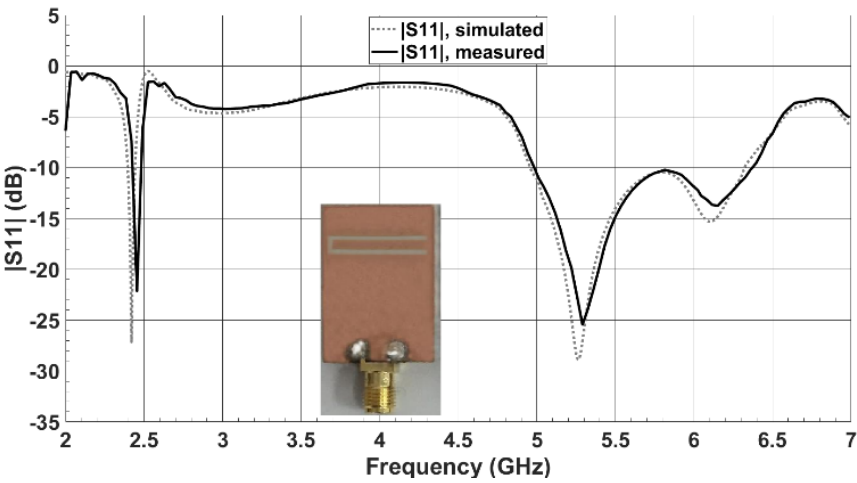

Fig. 8. Simulated and measured $\left|\mathrm{S}_{11}\right|$ of the proposed DRA with a U-shaped slot and without switching (case I).

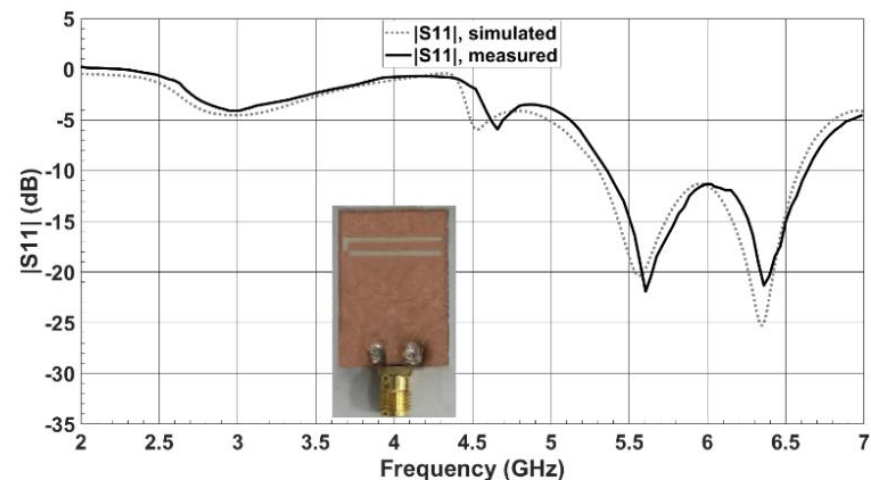

Fig. 9. Simulated and measured the $\left|S_{11}\right|$ of the proposed DRA with the first switch (case II).

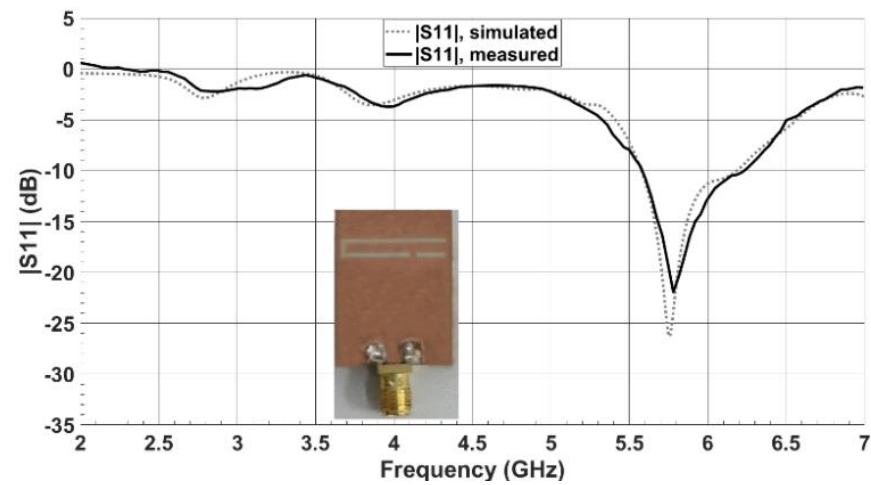

Fig. 10. Simulated and measured the $\left|S_{11}\right|$ of the proposed DRA with the second switch (case III) 
TABLE I. GAIN AND EFFICIENCY OF PROPOSED ANTENNA With AND WITHOUT DR BLOCK

\begin{tabular}{|c|c|c|c|c|c|c|}
\hline Frequency (GHz) & 2.4 & 5.23 & 5.55 & 5.8 & $\begin{array}{c}6.1 \\
1\end{array}$ & 6.35 \\
\hline Gain $(\boldsymbol{d B})$ & 2.89 & 3.43 & 3.52 & 3.03 & $\begin{array}{c}3.0 \\
6\end{array}$ & 2.97 \\
\hline Efficiency (\%) & 97 & 96 & 95 & 93 & 91 & 90 \\
\hline
\end{tabular}
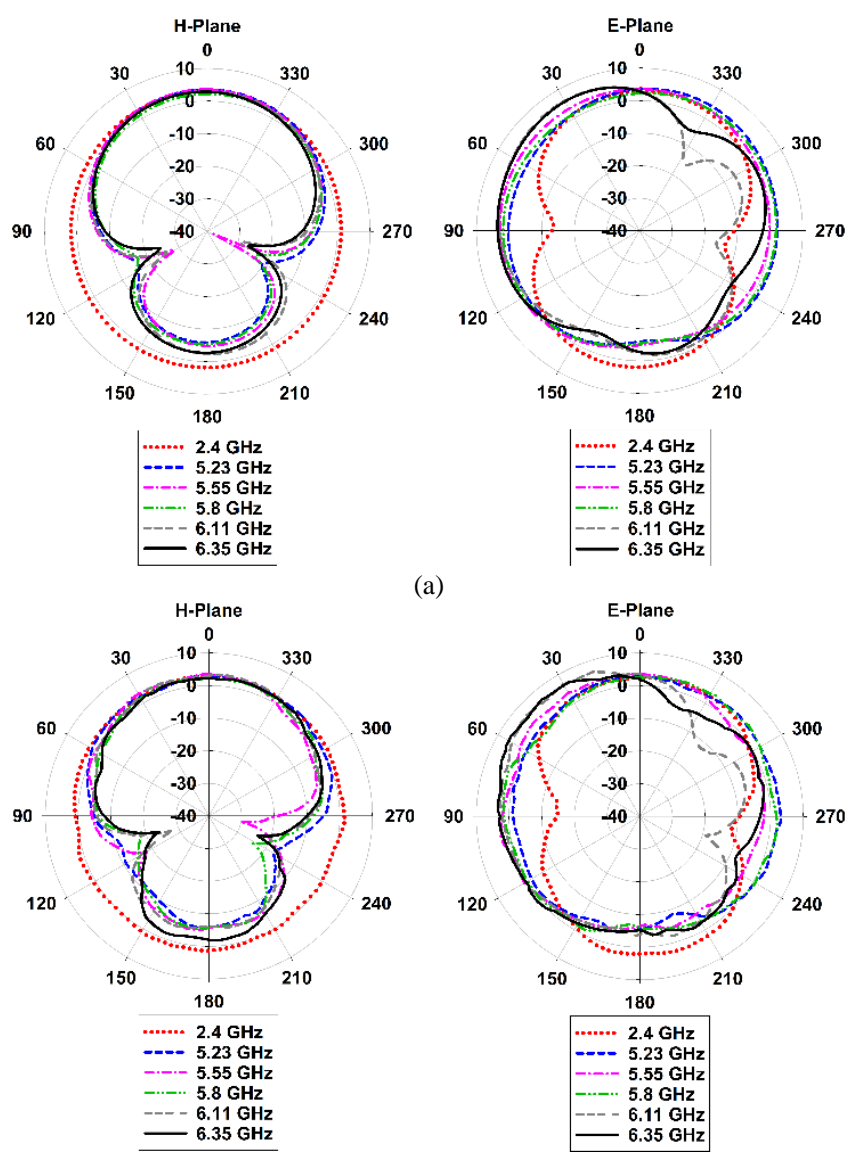

(a)

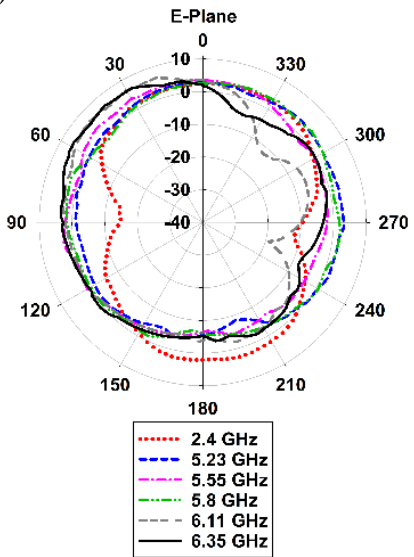

(b)

Fig. 11. Far-field radiation patterns of the proposed DRA at 6 different frequencies; (a) simulated and (b) measured.

In the first circumstance, case II, when switch located in the lower-left edge of the slot, antenna act as a wideband operation from $5.55 \mathrm{GHz}$ to $6.35 \mathrm{GHz}$. However, when the second switch (see Fig 4(b)) is situated, a single band bandwidth appears at $5.8 \mathrm{GHz}$. By considering the all three cases (case I, II, and III) and due to the fact that this antenna switches between two narrow and wideband operation, it can be valuable in some applications that need bandwidth switching like cognitive radio that requires a wideband antenna for performing the sensing function together with a narrowband antenna for handling communications. Thus, in order to save space, within a portable device, for instance, these two types of antennas should be integrated together as a reconfigurable antenna which able to switch between wideband and narrowband operation so fulfilling this requirement. Fig. 11 shows the radiation pattern of the proposed antennas at 6 different frequencies (case I $(2.4 \mathrm{GHz}$, $5.23 \mathrm{GHz}$, and $6.11 \mathrm{GHz})$, case II $(5.55 \mathrm{GHz}$ and $6.35 \mathrm{GHz})$, and case III $(5.8 \mathrm{GHz}))$ in xz-plane $\left(\phi=0^{\circ}\right)$ and yz-plane $(\phi$ $=90^{\circ}$ ). In general, there is a good agreement between the simulated and measured results. At $2.4 \mathrm{GHz}$, a typical monopole pattern is obtained: in the H-plane, almost omnidirectional, and in the E-plane with the typical 8-shaped.
These patterns get slightly more directive at higher frequencies, and tilting can be observed in the $\mathrm{H}$-plane. These phenomena arise from the fact that the radiation patterns of the proposed antenna are slightly affected by the monopole at the higher bands.

\section{CONCLUSION}

A novel reconfigurable dielectric resonator antenna has been presented and discussed. A T-shaped microstrip line was used as a feeding structure to excite the dielectric resonator, and the shorted stub was used to control the resonance frequencies. By etching an inverted U-shaped slot in the ground plane (case I), a dual-band operation, narrowband and wideband, is obtained. When the first switch placed at the lower-left edge of the slot (case II), two resonance frequencies at the upper band have been excited while when the second switch is applied (case III), the single-band operation has been obtained around $5.8 \mathrm{GHz}$. Proposed reconfigurable DRA can support both the lower and the upper band of the WLAN system. Moreover, this proposed structure is capable of switching its operating frequency bandwidth between wideband and narrowband, which suitable for some applications that require bandwidth switching like cognitive radio.

\section{REFERENCES}

[1] R. Kumar Mongia and A. Ittipiboon, "Theoretical and experimental investigations on rectangular dielectric resonator antennas," IEEE Trans. Antennas Propag., vol. 45, no. 9, pp. 1348-1356, Sept. 1997.

[2] S. Danesh, S. K. A. Rahim, and M. Khalily, "A Wideband Trapezoidal Dielectric Resonator Antenna with Circular Polarization," Prog. Electromagn. Res. Lett., vol. 34, pp. 91-100, 2012.

[3] M. Abedian, S. K. A. Rahim, S. Danesh, M. H. Jamaluddin, and M. T. Islam, "Compact wideband circularly polarised dielectric resonator antenna," Electron. Lett., vol. 53, no. 1, pp. 5-6, 512017.

[4] N. H. Shahadan et al., "Steerable Higher Order Mode Dielectric Resonator Antenna With Parasitic Elements for 5G Applications," IEEE Access, vol. 5, pp. 22234-22243, 2017.

[5] S. Danesh, M. R. Kamarudin, T. A. Rahman, M. Abedian, M. H. Jamaluddin, and M. Khalily, "A C-shaped dielectric resonator antenna with frequency reconfigurable for ISM and LTE band applications," Microw. Opt. Technol. Lett., vol. 59, No. 1, January 2017.

[6] M. Khalily, M. K. A. Rahim, A. A. Kishk, and S. Danesh, "Wideband P-shaped dielectric resonator antenna," Radioengineering, vol. 22, no. 1, pp. 281-285, 2013.

[7] M. Khalily, M. K. A. Rahim, and A. A. Kishk, "Planar wideband circularly polarized antenna design with rectangular ring dielectric resonator and parasitic printed loops," IEEE Antennas Wirel. Propag. Lett., vol. 11, pp. 905-907, 2012.

[8] M. Khalily, M. R. Kamarudin, and M. H. Jamaluddin, "A novel square dielectric resonator antenna with two unequal inclined slits for wideband circular polarization,” IEEE Antennas Wirel. Propag. Lett., vol. 12, pp. 1256-1259, 2013.

[9] M. Khalily, M. K. A. Rahim, and A. A. Kishk, "Bandwidth enhancement and Radiation Characteristics Improvement of Rectangular Dielectric Resonator Antenna," IEEE Antennas Wirel. Propag. Lett., vol. 10, pp. 393-395, 2010.

[10] M. Khalily, M. K. A. Rahim, N. A. Murad, N. A. Samsuri, and A. A. Kishk, "Rectangular ring-shaped dielectric resonator antenna for dual and wideband frequency," Microw. Opt. Technol. Lett., vol. 55, no. 5, pp. 1077-1081, 2013.

[11] M. Khalily and M. K. A. Rahim, "A novel hybrid design of printed hemi-cylindrical dielectric resonator monopole antenna with multibands operation," Prog. Electromagn. Res. C, vol. 15, pp. 175-186, 2010.

[12] Y. Gao, Z. Feng, and L. Zhang, "Compact asymmetrical T-shaped dielectric resonator antenna for broadband applications," IEEE Trans. Antennas Propag., vol 60, no. 3, pp. 1611-1615, 2012.

[13] X. L. Liang, T. A. Denidni, and L. N. Zhang, "Wideband L-shaped dielectric resonator antenna with a conformal inverted-trapezoidal 
patch feed," IEEE Trans. Antennas Propag., vol. 57, no. 1, pp. 271-274, 2009.

[14] K. S. Ryu, and A. A. Kishk, "UWB dielectric resonator antenna having consistent omnidirectional pattern and low cross-polarization characteristics," IEEE Trans. Antennas Propag. vol. 59, no. 4, pp. 1403-1408, 2011.

[15] R. D. Gupta and M. S. Parihar, "Investigation of an asymmetrical Eshaped dielectric resonator antenna with wideband characteristics," IET Microw. Antennas Propag., vol. 10, no. 12, pp. 1292-1297, 2016.

[16] S. Maity and B. Gupta, "Experimental investigations on wideband triangular dielectric resonator antenna," IEEE Trans. Antennas Propag., vol. 64, no. 12, pp. 5483-5486, 2016.

[17] X. L. Liang and T. A. Denidni, "Cross-T-shaped dielectric resonator antenna for wideband applications," Electron. Lett., vol. 44, no. 20, pp. 1176-1177, 2008.

[18] R. Chair, A. A. Kishk, K. F. Lee, "Low profile wideband embedded dielectric resonator," IET Microw. Antennas Propag., vol. 1, no. 2, pp. 294-298, 2007.

[19] A. A. Kishk, R. Chair, K. F. Lee, "Broadband dielectric resonator antennas excited by L-shaped probe," IEEE Trans. Antennas Propag., vol. 54, no. 8, pp. 2182-2189, 2006.

[20] R. K. Chaudhary, R. Kumar, and K. V. Srivastava, "Wideband ring dielectric resonator antenna with annular-shaped microstrip feed," IEEE Antennas Wirel. Propag. Lett., vol. 12, pp. 595-598, 2013.

[21] A. H. Majeed, A. S. Abdullah, F. Elmegri, and et al., "Aperturecoupled asymmetric dielectric resonators antenna for wideband applications," IEEE Antennas Wirel. Propag. Lett., vol. 13, pp. 927 930, 2014.

[22] S. Danesh, S. K. A. Rahim, M. Abedian, M. Khalily, and M. R. Hamid, "Frequency-Reconfigurable Rectangular Dielectric Resonator Antenna,” IEEE Antennas Wirel. Propag. Lett., vol. 12, pp. 1331-1334, 2013.

[23] S. G. O'Keefe and S. P. Kingsley, "Tunability of liquid dielectric resonator antennas," IEEE Antennas Wirel. Propag. Lett., vol. 6, pp. 533-536, 2007.

[24] S. Danesh, M. R. Kamarudin, T. A. Rahman, M. Abedian, and M. Khalily, "A wideband frequency reconfigurable rectangular dielectric resonator antenna," in Proc. 10th Eur. Conf. Antennas Propag. (EuCAP), Davos, 2016, pp. 1-4.

[25] T. Apperley and M. Okoniewski, “An Air-Gap-Based Frequency Switching Method for the Dielectric Resonator Antenna" IEEE Antennas Wirel. Propag. Lett., vol. 13, pp. 455-458, 2014.

[26] S. Danesh, S. K. A. Rahim, M. Abedian, and M. R. Hamid, “A compact Frequency Reconfigurable Rectangular Dielectric Resonator Antenna for LTE/WWAN and WLAN applications," IEEE Antennas Wirel. Propag. Lett., vol. 14, pp. 486- 489, 2015.

[27] S. Danesh, S. K. A. Rahim, and M. Abedian, "Frequency Reconfigurable Rectangular Dielectric Resonator Antenna for WiMAX/WLAN Applications" Microw. Opt. Technol. Lett., vol. 57, no. 3, pp. 579-582, 2015.

[28] J. Desjardins, D.A. McNamara, S. Thirakoune, and A. Petosa, "Electronically frequency-reconfigurable rectangular dielectric resonator antennas," IEEE Trans. Antennas Propag., vol. 60, pp. $2997-$ 3002, 2012.

[29] T. Apperley and M. Okoniewski, "An air-gap-based frequency switching method for the dielectric resonator antenna," IEEE Antennas Wirel. Propag. Lett., vol. 13, 455-458, 2014. 